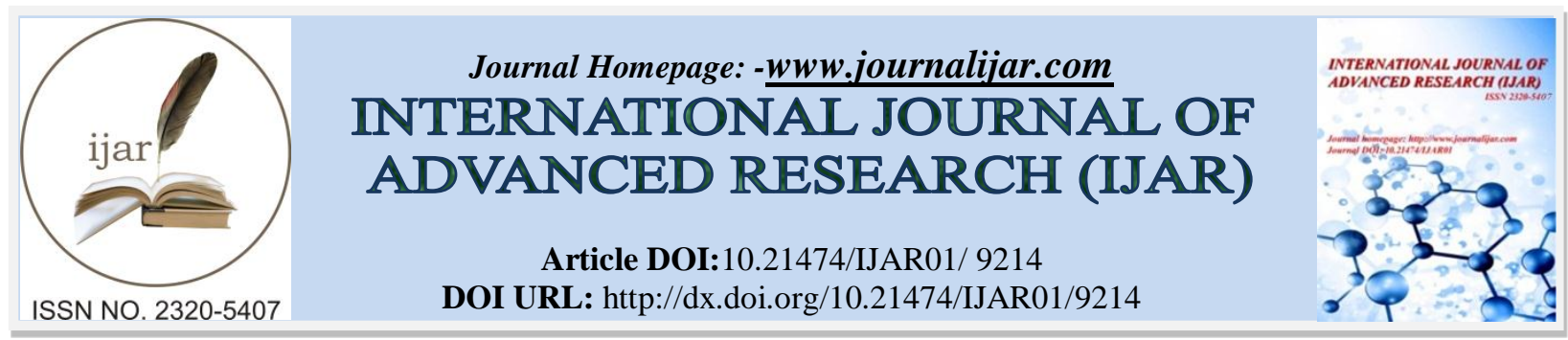

RESEARCH ARTICLE

\title{
A GIANT CYSTIC LYMPHANGIOMA OF THE RETROPERITONEUM AND PREGNANCY: A CASE REPORT.
}

\author{
Aboulfeth El Mehdi ${ }^{1}$, Lafquir Jaouad ${ }^{2}$, Bouzroud Mohamed ${ }^{1}$, Filali Karim ${ }^{3}$, Moujahid Mountassir, Tarchouli \\ Mohamed ${ }^{1}$ and Bounaim Ahmed ${ }^{1}$. \\ 1. Department of visceral surgery, military hospital of instruction Mohamed 5, Morocco. \\ 2. Department of gynecology obstetrics, military hospital instruction Mohamed 5, Morocco. \\ 3. Department of anesthesiology, First Medico-surgical Center of Agadir, Morocco.
}

\section{Manuscript Info}

........................

Manuscript History

Received: 05 April 2019

Final Accepted: 07 May 2019

Published: June 2019

Key words:-

Cystic lymphangioma, Retroperitoneum, Pregnancy, surgery.

\section{Abstract}

Background: Cystic lymphangioma is a rare benign malformative tumor of lymphatic vessels in various locations. The retroperitoneal localization is less common compared to mesenteric one. Its clinical presentation is polymorphic and its discovery on the occasion of a pregnancy has rarely been described.

The diagnosis is evoked by imaging but requires histological confirmation. Surgery is the treatment of choice.

Case report: 22-year-old female presented for pregnancy control. Her clinical examination and ultrasounds reveled a giant abdominal cyst fulling the entire abdomen and exposing the pregnant for miscarriage. Surgical removal under laparotomy was carried out and the patient 's postoperative recovery was uneventful. The giant cyst was diagnosed as a retroperitoneal cystic lymphangioma.

Conclusion: we are reporting this rare case to share our experience in its management. The complete surgical removal of the cyst is possible even if it seems to encase major vessels as a clean plane of dissection usually exists.

Copy Right, IJAR, 2019,. All rights reserved.

\section{Introduction:-}

Cystic lymphangioma is a rare benign tumor of lymphatic vessels in various locations. The retroperitoneal localization is less common compared to mesenteric. its clinical presentation is polymorphic. its discovery on the occasion of a pregnancy has rarely been described.

The diagnosis is evoked by imaging but requires histological confirmation. Surgery is the treatment of choice. Because of its rarity, the diagnostic and treatment dilemma that it poses when associated to a pregnancy, we are reporting a case of giant retroperitoneal cystic lymphangioma in a 22-year-old pregnant female.

\section{Case report}

A 22 years old female, recently married, with no medical records, first presented to the gynecology department for pregnancy control. She accused for a year and a half a progressive increase of the abdominal volume and anorexia without pain or other associated signs, in discordance with her eight weeks of amenorrhea. 
the clinical examination finds a moderately built patient, with an apparent abdominal fullness on inspection. A giant mass occupying the entire abdomen was palpable. The mass has a smooth surface, lower and upper margins were impossible to reach on palpation, with a firm cystic consistency and reduced mobility in all directions but which remains painless. There was no inguinal lymphadenopathy.

speculum examination shows a healthy cervix without bleeding. the vaginal digital touch shows a long and closed cervix.

Endo-vaginal ultrasound found a gestational sac consistent of 10 weeks with positive cardiac activity. The right ovary was free, the left one was not seen, masked by a voluminous intra peritoneal cyst with homogeneous content. (Figure1)

The pelvic abdominal MRI showed a very voluminous intra peritoneal abdominopelvic cystic tumor measuring approximately $40 \mathrm{~cm}$ in length and $27 \mathrm{~cm}$ in transverse diameter and $18 \mathrm{~cm}$ in antero-posterior diameter. This cyst has a globally homogenous fluid content in strong hypersignal in $\mathrm{T} 2$, hyposignal in $\mathrm{T} 1$, multiloculated containing multiple thin septa without significant fleshy component. the upper pole of the cyst was reaching the level of the gall bladder which was pushed back slightly inwards, pushed the right kidney upwards and inwards against the rachis with dilatation of its pyelocaliciel cavities resecting the cortical index and dilation of the right ureter until at the level of the iliac pedicle ,the left kidney was slightly pushed back without dilation of its excretory cavities. Laterally, the mass occupied the entire flank and was pushing the Bowel into the left hypochondrium. The lower pole of the mass arriving in the pelvis pushed the gravid and retroverted uterus backwards slightly to the left. aspect first evoking a cystic lymphangioma.(Figure 2) Biological findings were all normal.

the patient was quickly scheduled for surgery after adequate tocolysis on progestogen . Upon laparotomy, there was a giant multi-cystic retroperitoneal mass $(40 \times 30 \mathrm{~cm})$, pushing the intestines in the left hypochondrium and the liver up, down it pushes a gravid and globular uterus to the left, both ovaries were free (Figure 3). This mass, with apparently two major cysts, was in contact with almost all the noble elements of the retro peritoneum; ureter of both sides, gonadal vessels and large vessels (vena cava and aorta with their bifurcations).

the size of the mass girdles the surgical exploration, and considering its appearance very probably benign, we decided to empty the two large cysts, which contained respectively 6 and 5 liters of a clear yellow citrine liquid.

(Figure 4)

There was a plane of dissection among the vessels (large, gonadics and mesenteric), ureters, and the cyst, which was dissected free completely using sharp and blunt dissection. (Figure 5)

the retroperitoneum and the mesentery were inspected closely for any remnants. The bowel was inspected and was found to be healthy, viable.

The postoperative course was uneventful and Ultrasound redone 48 hours after surgery confirmed fetal viability. Histologically, the mass was cystic formation lined by a regular cubic cell base devoid of cyto-nuclear atypia this seat is subtended by a fibrous connective tissue comprising congestive vessels (figure 6). a cytospin performed on the intracystic fluid sample, corespond after technique and staining to histocytic cells, inflammatory cells, macrophages and some neutrophil polynuclear cells without cells suspected of malignancy

Thus, the diagnosis of a retroperitoneal multilocular cystic lymphangioma was confirmed.

\section{Discussion:-}

Two theories have been proposed as to the origin of cystic lymphangioma:

The first suggests an acquired origin resulting from an obstruction of the lymphatic vessels as a result of inflammation, trauma or degeneration [1].

The most probable hypothesis of the development of a cystic lymphangioma is a congenital malformative origin [2].

The formation of a cyst is the evolution of a lymphatic bud secondary to a lack of connection, during embryogenesis, between lymphatic chains and the venous system $[2,3]$.

The retroperitoneal localization of cystic lymphangioma is less frequent compared to mesenteric localization [4] 
The clinical presentation of cystic lymphangioma in adults is variable [5], ranging from an often-asymptomatic mass to an acute abdominal pain or even to complications such as rupture, infection, intravenous hemorrhage, occlusion, cystic torsion, compression or infiltration of vital structures, the malignant transformation is exceptional [4]. No sign is specific and it is the imaging assessment that will guide the diagnosis [6].

in our case; the mass was asymptomatic, but our patient was pregnant, the huge volume of the mass constituted a real risk of miscarriage; the surgical removal was therefore an emergency. Ultrasonography shows cystic lymphangioma as a well-defined fluid tumor or multilocular, the cysts being separated, in this case, by thin septa. The content of the cysts, often transonic, can however become echogenic during an intra-cystic hemorrhage or even contain some calcifications [7]. In our case MRI finds its best indications, making it possible to study the relations with the neighboring organs and also allows an accurate diagnosis, to better specify the nature of the contents of the cysts [2] and to appreciate it very well of the perivascular extension of the lesion [ 3,7]

MRI however, due to the size of the cyst, was not very helpful in confirming its retroperitoneal localization, which could only be observed during surgical exploration.

recurrence is common for aspirated cysts with or without sclerotic injection $[2,8]$

Surgery of removal, upon laparotomy or laparoscopic, is the classic attitude in abdominal localization [2, 9,10].

laparoscopy was technically difficult because of the size of the cyst, its retro-peritoneal relationships and pregnancy.

The surgical removal should be conservative and as complete as possible to avoid recurrence [3,10] the lymphostasis must be meticulous, the recurrence rate is $40 \%$ after incomplete resection and $17 \%$ after macroscopically complete resection, all locations combined [2,8].

Evoked by the clinic, suspected by imaging and worn during the intervention, the diagnosis of cystic lymphangioma can only be confirmed during the histological examination.

Histologically, retroperitoneal lymphangioma consists of cavities lined by an endothelium resting on fibrous tissue containing lymphocytic lymphocytes and sometimes smooth muscle fibers. Inflammation and hemorrhage often cause reshaping with disappearance of the endothelium, appearance of fibrin deposits, sometimes making the histological diagnosis impossible on simple biopsies [7].

\section{Conclusion:-}

Retroperitoneal cystic lymhangioma is a rare begnin tumor in adults. cyst size and pregnancy were decisive for the surgical approach. The complete removal of the cyst is possible even if it seems to encase major vessels as a clean plane of dissection usually exists. the surgical excision of this mass allowed the persuit of the pregnancy without risk.

\section{Consent}

Written informed consent was obtained from the patient for publication of this case report and any accompanying images. A copy of the written consent is available for review by the Editor of this journal.

\section{Conflict of Interests}

The authors declare that there is no conflict of interests regarding the publication of this paper. Authors' Contributions

All authors participated in the care of the patient and the writing of the manuscript. All authors have read and approved the final version of the manuscript. 


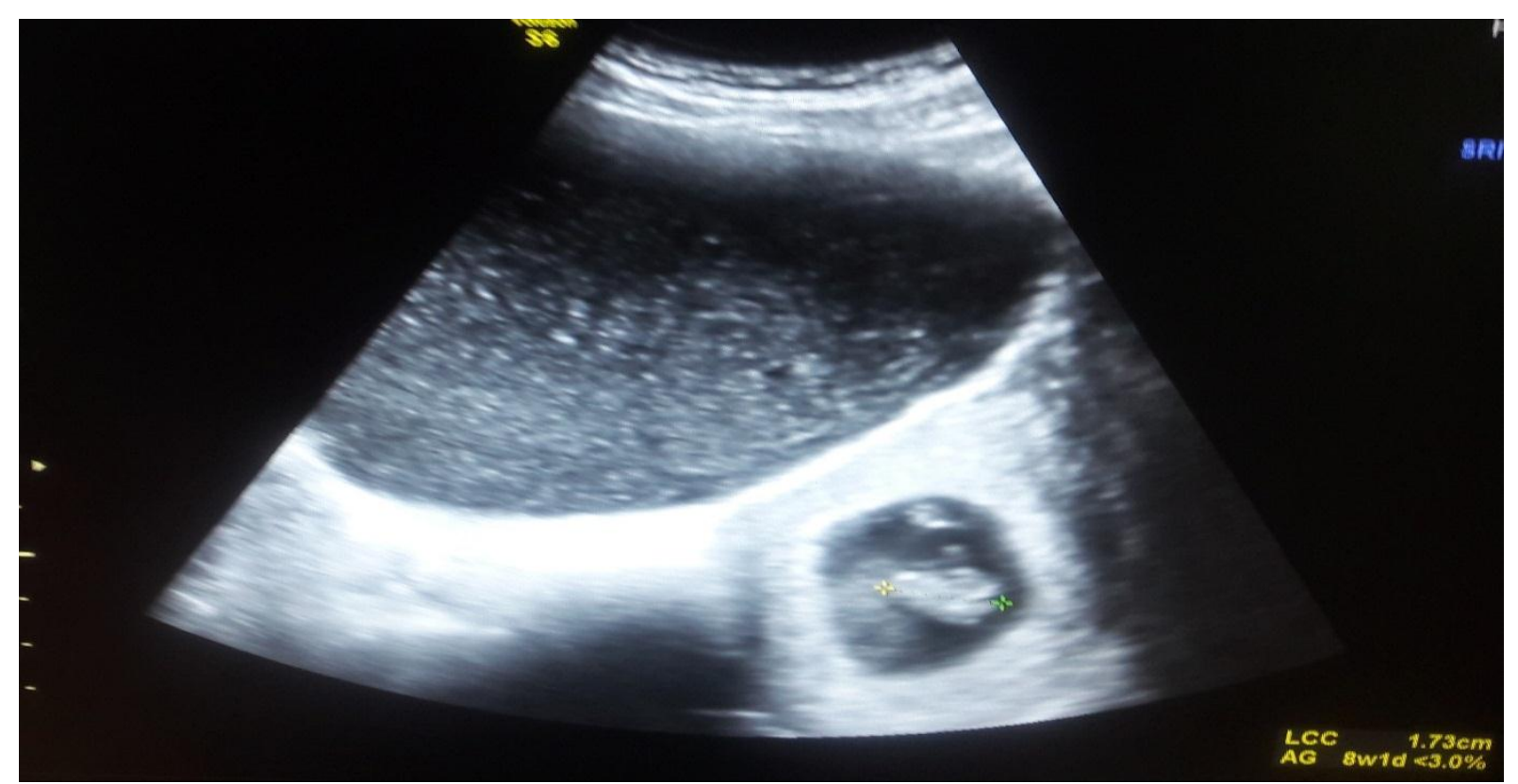

Figure 1:-Ultrasound examination showing a giant cyst pushing a gravide uterus.

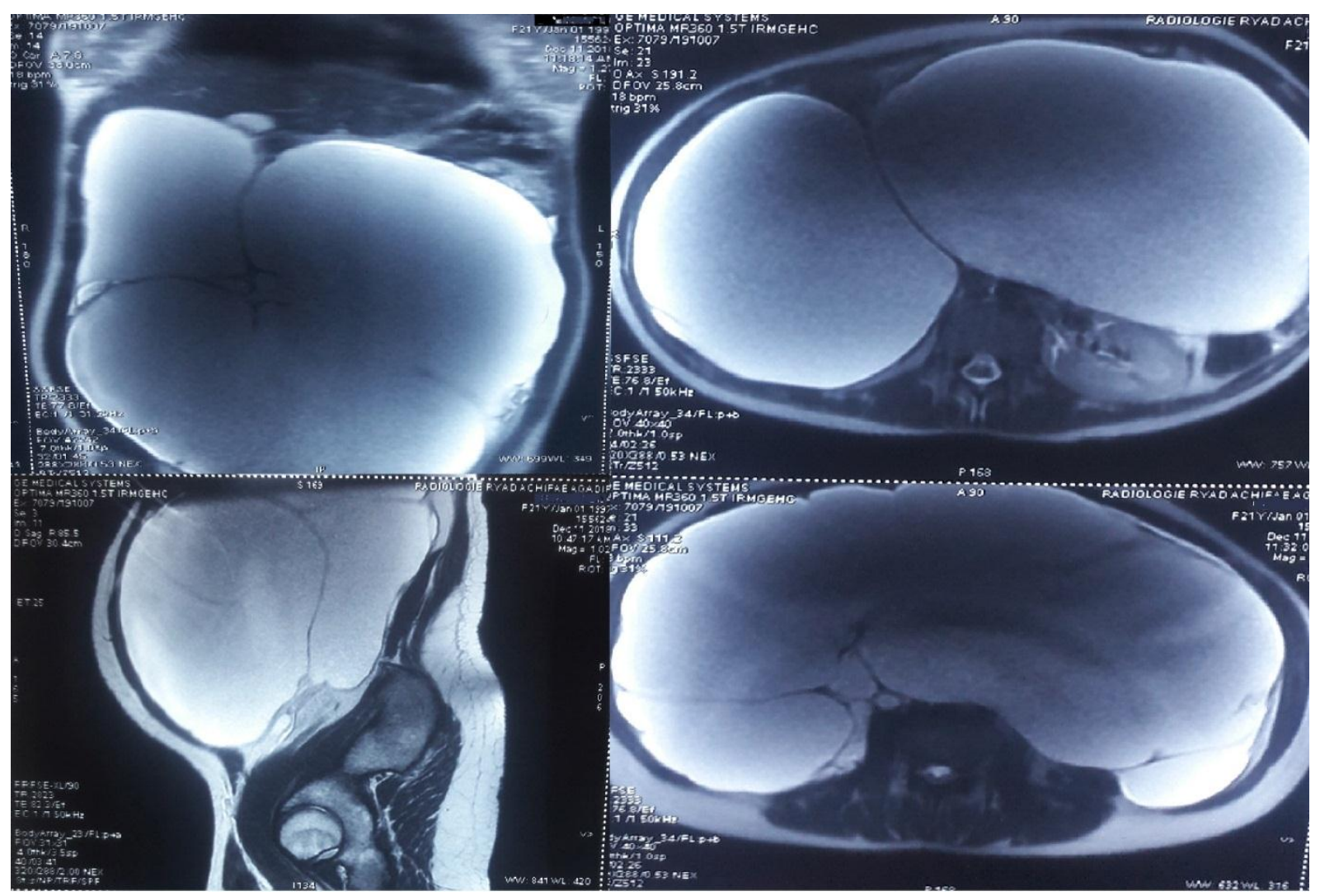

Figure 2 :-MRI examination showing a giant homogenous cyst fulling the entire abdomen . 


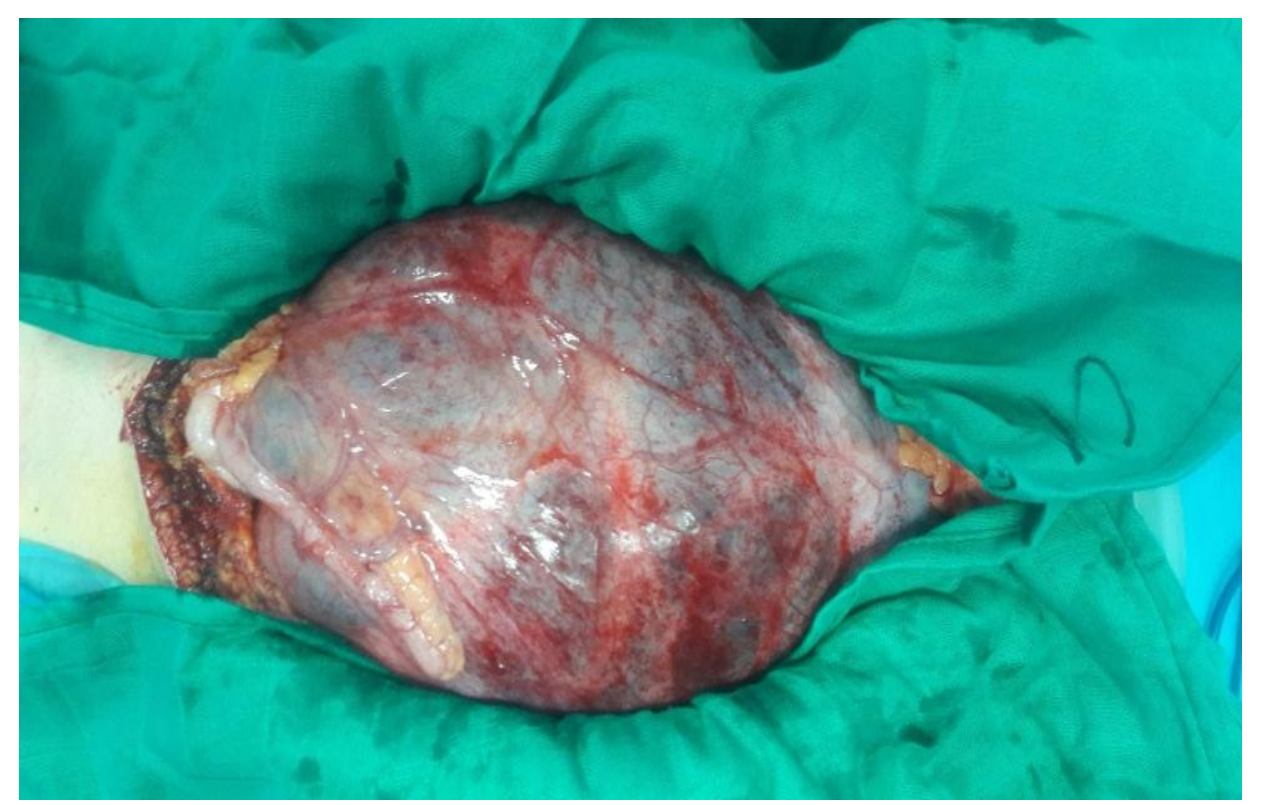

Figure 3:-Per operative image showing the retroperitoneal location of the cyst, the appendix lays on the mass.

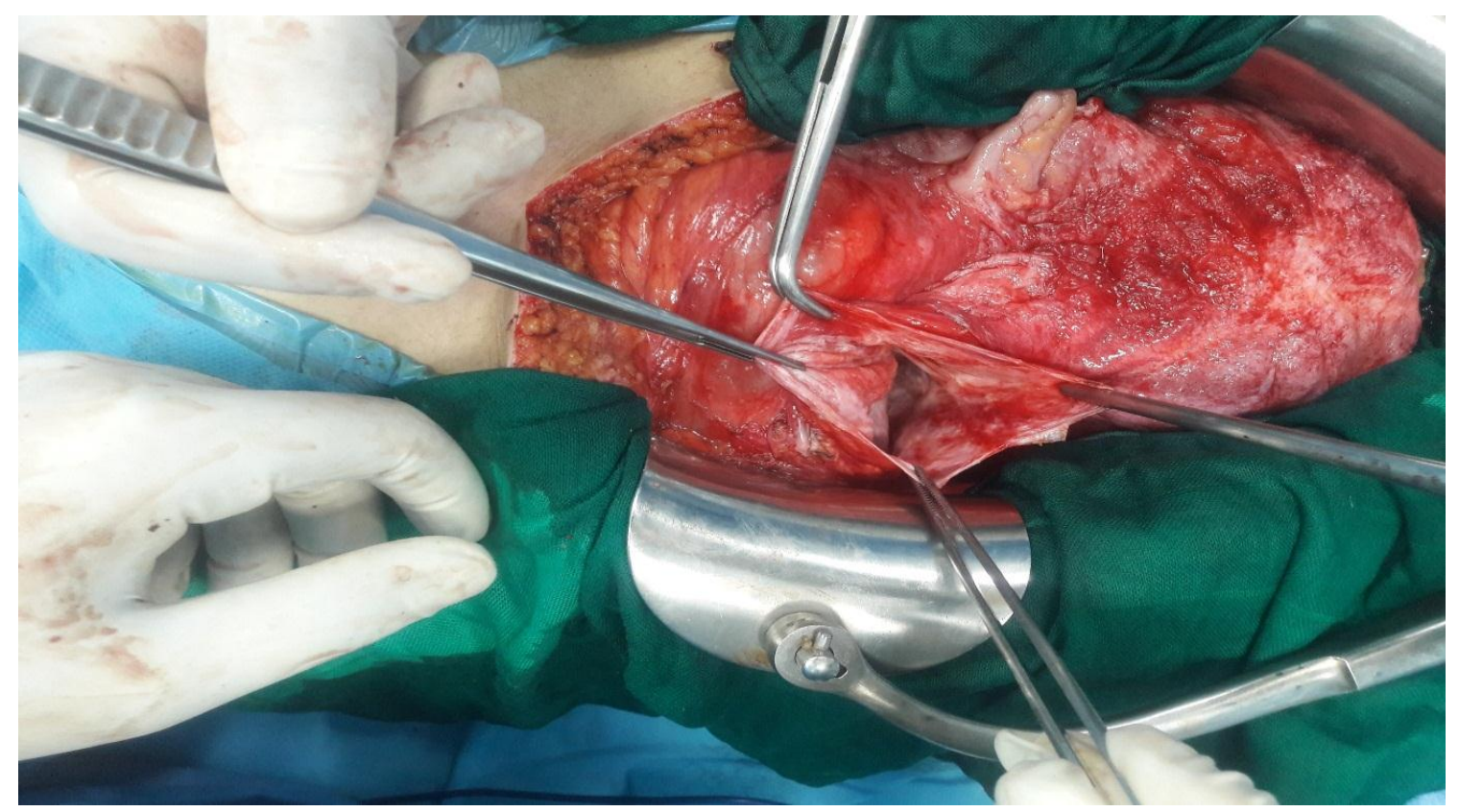

Figure 4:-Per operative image showing the inside versant of the empty cyst. 


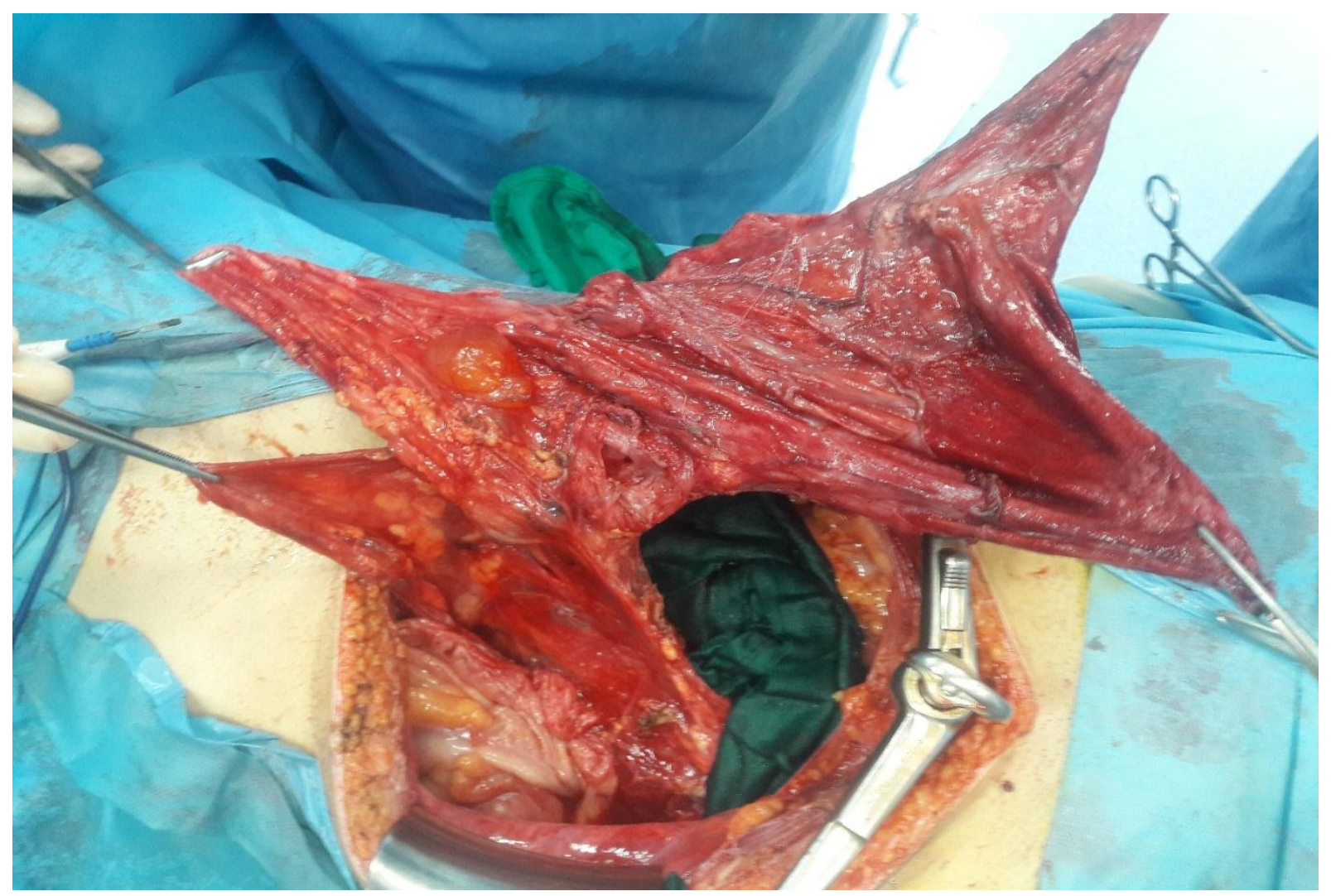

Figure 5:-Per operative image showing the "enbloc" removal of the cyst wall .
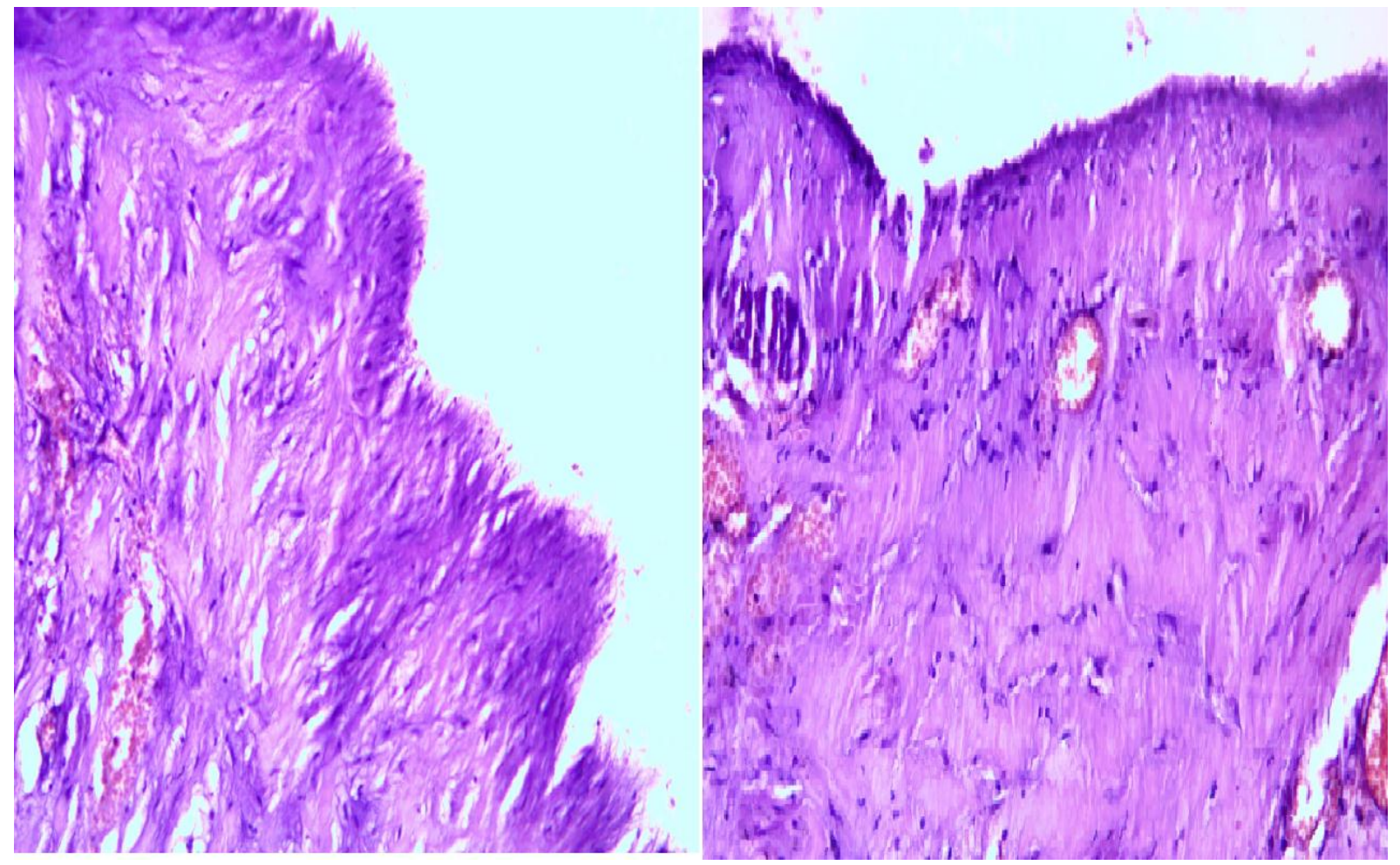

Figure 6:-histological examination confirming the lymphangioma cyst of the retroperitoneum 


\section{Reference:-}

1. Bonhomme A, Broeders A, Oyen RH, Stas M, De Wever I, Baert AL. Cystic lymphangioma of the retroperitoneum. Clin Radiol. 2001; 56(2):156-158. PubMed | Google Scholar (1)

2. Bezzola T, Bühler L, Chardot C, Morel P. Le traitement chirurgical du lymphangiome kystique abdominal chez l'adulte et chez l'enfant. J Chir (Paris). 2008; 145(3):238-243. PubMed | Google Scholar

3. Rifki Jai S, Adraoui J, Khaiz D, Chehad F, Lakhloufi A, Bouzidi A. Le lymphangiome kystique rétropéritonéal. Prog Urol. 2004; 14(4):548-550. PubMed | Google Scholar

4. DEBAT ZOGUEREH D.,TARUNDEGA U.N.,PROVENDIER B. : Une volumineuse masse rétropéritonéale chez un adulte. La revue de la médecine interne, $2003 ; 24: 202-203$.

5. Losanoff JE, Richman BW, El-Sherif A. Mesenteric cystic lymphogioma. J Am Coll Surg. 2003 ; 196(4): 598603. PubMed | Google Scholar (5)

6. Mabrut JY, Grandjean JP, Henry L, Chappuis JP, Partensky C, Barth X, Tissot E. Mesenteric and mesocolic cystic lymphangiomas: Diagnostic and therapeutic management. Ann Chir. 2002; 127(5):343-349. PubMed| Google Scholar

7. Ravasse P., LE TREUST M., LEVESQUE C. : Le lymphangiome kystique rétropéritonéal : une tumeur d'expression clinique très polymorphe. A propos de 3 cas. Arch. Pédiatr. $1995 ; 2: 232-236$.

8. Alqahtani A, Nguyen LT, Flageole H, Shaw K, Laberge JM. 25 years? experience with lymphangiomas in children. J Pediatr Surg. 1999; 34(7):1164-1168. PubMed | Google Scholar

9. Konen O, Rathaus V, Dlugy E, Freud E, Kessler A, Shapiro M, Horev G. Childhood abdominal cystic lymphangioma. Pediatr Radiol. 2002; 32(2):88-94. PubMed | Google Scholar

10. De Perrot M, Rostan O, Morel P, Le Coultre C. Abdominal lymphangioma in adults and children. Br J Surg. 1998; 85(3):395-397. PubMed | Google Scholar. 